\title{
Dive depths of Weddell seals in relation to vertical prey distribution as estimated by image data
}

\author{
Yuuki Watanabe ${ }^{1, *}$, Yoko Mitani ${ }^{2}$, Katsufumi Sato ${ }^{2,3}$, Michael F. Cameron ${ }^{4,5}$, \\ Yasuhiko Naito ${ }^{2,3}$ \\ ${ }^{1}$ Otsuchi Marine Research Center, Ocean Research Institute, The University of Tokyo, 2-106-1 Akahama, Otsuchi, \\ Iwate 028-1102, Japan \\ ${ }^{2}$ National Institute of Polar Research, and ${ }^{3}$ Graduate University for Advanced Studies, 1-9-10 Kaga, Itabashi, \\ Tokyo 173-8515, Japan \\ ${ }^{4}$ Department of Ecology, Evolution, and Behavior, University of Minnesota, 100 Ecology, St. Paul, Minnesota 55455, USA
}

${ }^{5}$ Present address: National Marine Mammal Laboratory, Alaska Fisheries Science Center, NOAA, 7600 Sand Point Way NE, Seattle, Washington 98115, USA

\begin{abstract}
To better understand the foraging behavior of diving animals it is important to monitor aspects of the animal's environment, including prey distribution, which may influence their behavior. However, prior to recent technological advancements, monitoring the distribution of prey immediately surrounding a diving animal had been impossible. We attached newly developed Digital Still picture Loggers (DSLs) to 8 free-ranging female Weddell seals Leptonychotes weddellii at breeding colonies in McMurdo Sound, Antarctica, from November to December 2000. The DSLs provided depth data and several thousand underwater images taken from the seals' perspectives. Some of these images clearly showed scattered prey-like objects directly in front of the seal. Using image processing software, the images were converted to a 256 gray-scale and the prey-like objects were identified according to their brightness ratio and counted. Finally, a 'prey index' was calculated for each image and the vertical prey distribution along the seals' dive paths were compared with the seals' dive depth. Seals frequently dived to depths greater than $250 \mathrm{~m}$ where the prey index was both higher and exhibited a wider range. We concluded that the seals' dive depths might be affected by the vertical distribution of prey, which appeared to be aggregated in shoals at deeper depths.
\end{abstract}

KEY WORDS: Foraging behavior - Vertical prey distribution - Digital Still picture Loggers · Prey index $\cdot$ Weddell seals

\section{INTRODUCTION}

The development and use of animal-borne timedepth recorders (TDRs) has provided data on many parameters (e.g. maximum and mean dive depth, descent rate, bottom time, ascent rate, dive duration, surface time) useful for investigating the diving behavior of marine mammals (Kooyman 1968, Naito et al. 1989). However, marine mammals, like all animals, interact with and respond to their environment. Therefore, information on an animal's immediate surroundings is important to better understand what may affect their diving behavior. In particular, detailed information on the biological environment, such as prey distri- bution, is essential to the foraging studies of diving animals.

Investigators have recently begun to utilize video systems attached to animals to study the underwater feeding behavior of predators (Davis et al. 1992, 1999, Ponganis et al. 2000, Fuiman et al. 2002). These systems are useful for observing underwater feeding behaviors in detail, but due to restrictions in the amount of digital memory or length of videotape, the data records cover a relatively short period of time when recording continuously (e.g. $2 \mathrm{~h}$ for Davis et al. 1992; $1 \mathrm{~h}$ for Ponganis et al. 2000; 6 h for Fuiman et al. 2002). Recording multiple dive bouts from the same individual requires the animal to be recaptured and a new video system to be at- 
tached. Usually this is facilitated by moving the animal from a breeding colony to an isolated hole in the fast ice. In contrast, the Digital Still picture Logger (DSL) that we recently developed can record still images from free-ranging seals for up to $2 \mathrm{~d}$ without the need to relocate the animal. The DSL is designed to record image data on a pre-programmed sampling interval, and only when the depth exceeds a preset threshold $(30 \mathrm{~s}$ and $5 \mathrm{~m}$ respectively in this study). An isolated hole is therefore not necessary and as a result the DSL can be used under natural conditions.

Hooker et al. (2002) recognized the presence of krill swarms within the field of view of diving animals instrumented with a digital camera, and the underwater DSL images of Sato et al. (2002) revealed that Weddell seals Leptonychotes weddellii would stretch their necks to capture fish and other prey-like objects. In the present study, we attached DSLs onto free-ranging Weddell seals and, by counting the number of prey-like objects on the still images, estimated the relative prey abundances.

\section{MATERIALS AND METHODS}

DSL. A DSL-1000DV camera (Little Leonardo) provided the underwater still images. The camera weighed $3.4 \mathrm{~kg}$ in air (approximately $1 \%$ of a seal's body mass) and $1.6 \mathrm{~kg}$ in water. The camera was pressure-resistant to a depth of $2000 \mathrm{~m}$. The DSL was composed of 2 cylin-

\section{(a) Study area}

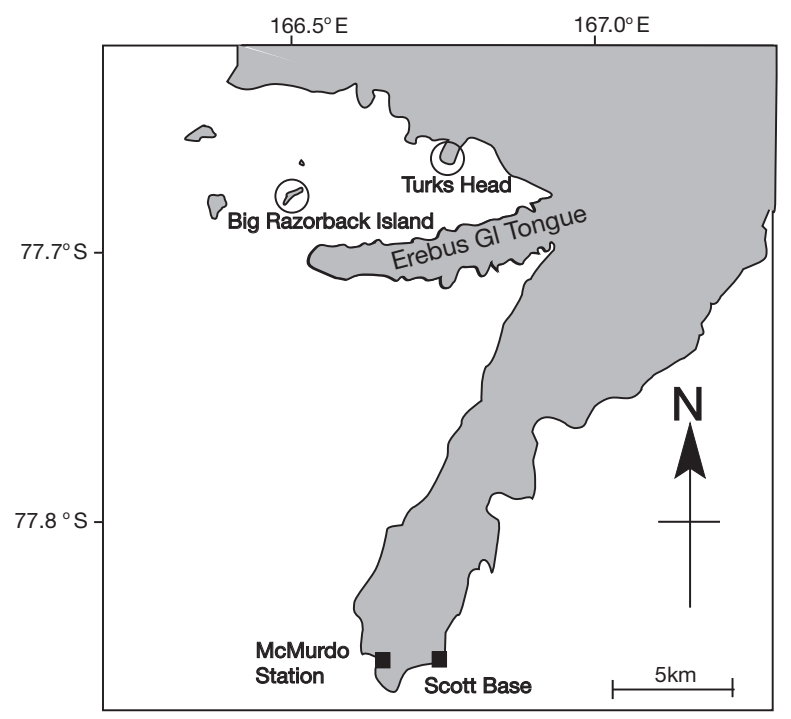

Fig. 1. (a) Location of the study areas (open circles) near the vicinity of McMurdo Station, Antarctica. Land is represented by gray color. The sea (white) was covered by fast ice during the duration of the study. Bathymetric diagram of (b) Big Razorback Island and (c) Turks Head. The ice holes and tidal cracks are shown by black horizontal bars (b and c) drical housings, each $230 \mathrm{~mm}$ in length and $52 \mathrm{~mm}$ in diameter. One housing contained the color digital camera (minimum illumination 8 lux; angle of view $45^{\circ}$; effective resolution $510 \times 492$ pixels; automatic white balance), an onboard microcomputer with $64 \mathrm{MB}$ of flash memory and $3 \times 1.5 \mathrm{~V}$ lithium batteries. The other housing contained a flash (guide number 32 ) and $4 \times$ $1.5 \mathrm{~V}$ lithium batteries. In complete darkness, the onboard microcomputer synchronized the flash and camera. An automatic gain controller determined the exposure in all conditions. The depth of focus was between $10 \mathrm{~cm}$ and infinity. The onboard microcomputer maintained a pre-programmed sampling interval of $30 \mathrm{~s}$ and a pressure-sensed depth threshold of $5 \mathrm{~m}$. The camera was able to store approximately 700 images, and recorded depth data at $1 \mathrm{~s}$ intervals (maximum depth $1000 \mathrm{~m}$, resolution $1 \mathrm{~m}$, absolute accuracy $\pm 5 \mathrm{~m}$ ).

Field experiments. These were conducted from November 10 to December 12, 2000, at 2 breeding colonies: Big Razorback Island $\left(77.68^{\circ} \mathrm{S}, 166.50^{\circ} \mathrm{E}\right)$ and Turks Head $\left(77.67^{\circ} \mathrm{S}, 166.78^{\circ} \mathrm{E}\right)$, in the region of McMurdo Sound, Ross Island, Antarctica (Fig. 1a). Both breeding sites are covered by fast ice during the breeding season. Tidal cracks or holes drilled through the sea ice facilitated the use of a depth gauge (Type-8, Tsurumi Seiki) to measure the bathymetry of each study site and analyze how it affected each seal's diving behavior. Weddell seals use naturally occurring cracks to enter the water from the surface of the sea

\section{(b) Big Razorback Island}

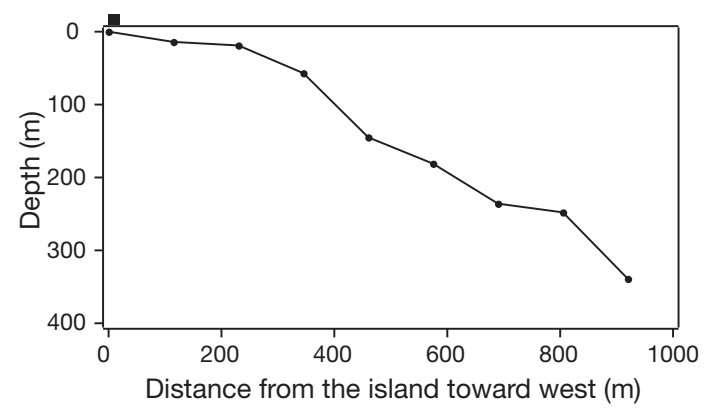

(c) Turks Head

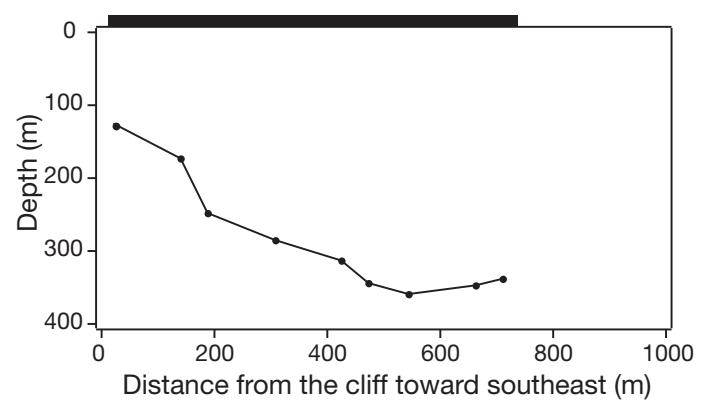


ice. At Big Razorback Island, these cracks are oriented close and parallel to the coastline of the island. As such, to reach deep water seals must swim at an angle and follow the slope of the island (Fig. 1b). In contrast, the primary crack at Turks Head is perpendicular to the coastline and over deep water. Additionally, the underwater slope at Turks Head is much steeper than at Big Razorback Island and seals along this crack may dive vertically to reach deeper depths (Fig. 1c). The DSLs were attached to 4 free-ranging Weddell seal females at each breeding colony. Seals were first captured using the head bag technique of Stirling (1966). Then the inhalant sevoflurane was used to anaesthetize and chemically restrain the animal for the attachment of the instruments (Kusagaya \& Sato 2001). The DSL was attached to the back of the seal using an epoxy resin (Evercoat Ten-set; Fiber Glass-Evercoat). The animal was then released and the DSL was retrieved 1 or $2 \mathrm{~d}$ later at the same colony where it was attached. Any remaining adhesive was expected to fall off with the pelage during the seal's next molt.

Data analysis. Sato et al. (2002) showed that dives greater than $50 \mathrm{~m}$ were correlated with foraging. Therefore, only dives with a maximum depth greater than $50 \mathrm{~m}$ were used in the analysis. Each dive was subdivided into a descent phase (from the beginning of a dive to the time of the first ascent while deeper than $50 \mathrm{~m}$ ), an ascent phase (from the depth of the last descent while deeper than $50 \mathrm{~m}$ to the end of dive), and a bottom phase (the time between the end of descent and beginning of ascent).

Images showing the sea bottom (Fig. 2) or sea ice were omitted from the analysis as the lighter color of these features obscured the presence of prey. In McMurdo Sound, Pleuragramma antarcticum makes up more than $90 \%$ of the fish biomass (DeWitt 1970, Everson 1984, Eastman 1985, Macdonald et al. 1987) and therefore is considered to be the major prey of the local Weddell seal population (Castellini et al. 1984, Green \& Burton 1987, Burns et al. 1998, Fuiman et al. 2002). The images from the DSLs showed many whitish objects (Fig. 3a), and in some cases an actual capture event was recorded (Sato et al. 2002). We assumed that these objects were prey, potentially $P$. antarcticum. They were digitally isolated, identified and counted using image processing software (WinROOF Version 3.53: Mitani), and variations in their brightness were determined. This was accomplished by first excluding the large white object (the other data logger in front of the DSL) on the lower-left corner of the image from the analysis using a mask (Fig. 3b). Second, each image was converted to a 256 gray-scale (Fig. 3c), and the overall brightness of the background (darker on the right side because of the camera layout and flash position) was made uniform across all images

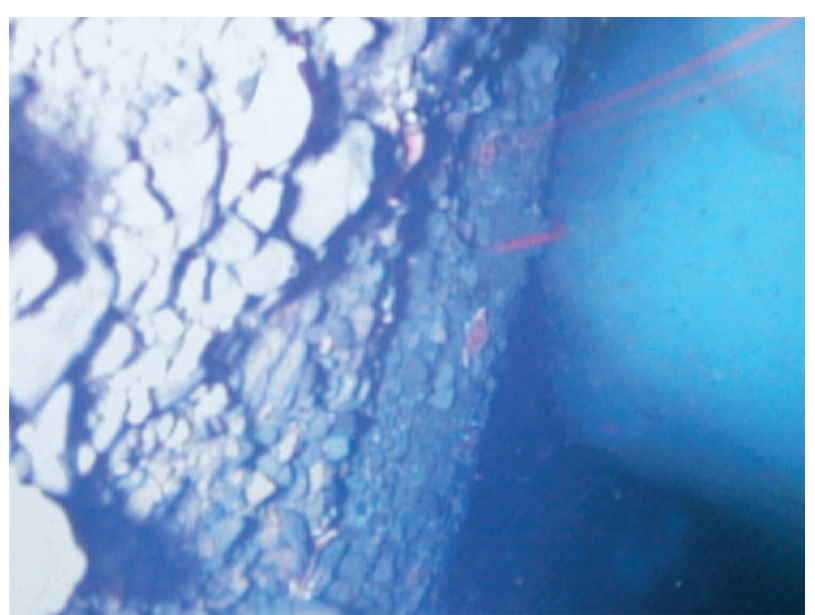

Fig. 2. Image showing the sea bottom, taken by the Digital Still picture Logger (DSL) attached to the seal referred to as 'Flaca', at 6 m depth. The seal was rolling on its side when the image was taken

using a function of the software (Fig. 3d). Finally, the prey-like objects were isolated and identified using a brightness threshold (66\% of maximum brightness) for all images (Fig. 3e). This threshold was chosen to reduce the likelihood of falsely counting background scatter as a prey object. The number of objects was counted and a prey index was calculated for each slide. The index was defined as:

$$
\text { Prey index }=\left(A_{\mathrm{o}} / A_{\mathrm{a}}\right) \times\left(\mathrm{n} \times A_{\mathrm{w}} / A_{\mathrm{a}}\right)
$$

where $A_{\mathrm{o}}=$ total area occupied by objects, $A_{\mathrm{a}}=$ available area which excluded the area of the other data logger, $\mathrm{n}=$ number of objects, and $A_{\mathrm{w}}=$ whole area of the image (Fig. 3e). Statistical analysis was performed using Stat View, Version 4.5. Values for significance were set at $\mathrm{p}<0.05$. Means are reported as $\pm 1 \mathrm{SD}$.

\section{RESULTS}

Depth and image data were obtained from 8 seals and the mean duration over which data were collected was $25.8 \mathrm{~h}$. Each of the instrumented Weddell seals conducted 5 to 16 dives with a maximum depth greater than $50 \mathrm{~m}$ (Table 1). The mean dive depth of seals studied at Big Razorback Island was 231.9 $\pm 94.4 \mathrm{~m}$, ranging from $203.4 \pm 69.9$ to $278.6 \pm 18.0 \mathrm{~m}$, while the mean dive depth at Turks Head was $295.2 \pm 76.3 \mathrm{~m}$, ranging from $263.9 \pm 65.9$ to $314.2 \pm 27.3 \mathrm{~m}$. Maximum dive depth for seals at Big Razorback Island was significantly shallower than at Turks Head (Mann-Whitney U-test, p < 0.0001). The frequencies of dive depths were summed for each site (Fig. 4a,b). These distributions showed a mode between 250 and $300 \mathrm{~m}$ for seals at Big Razor- 


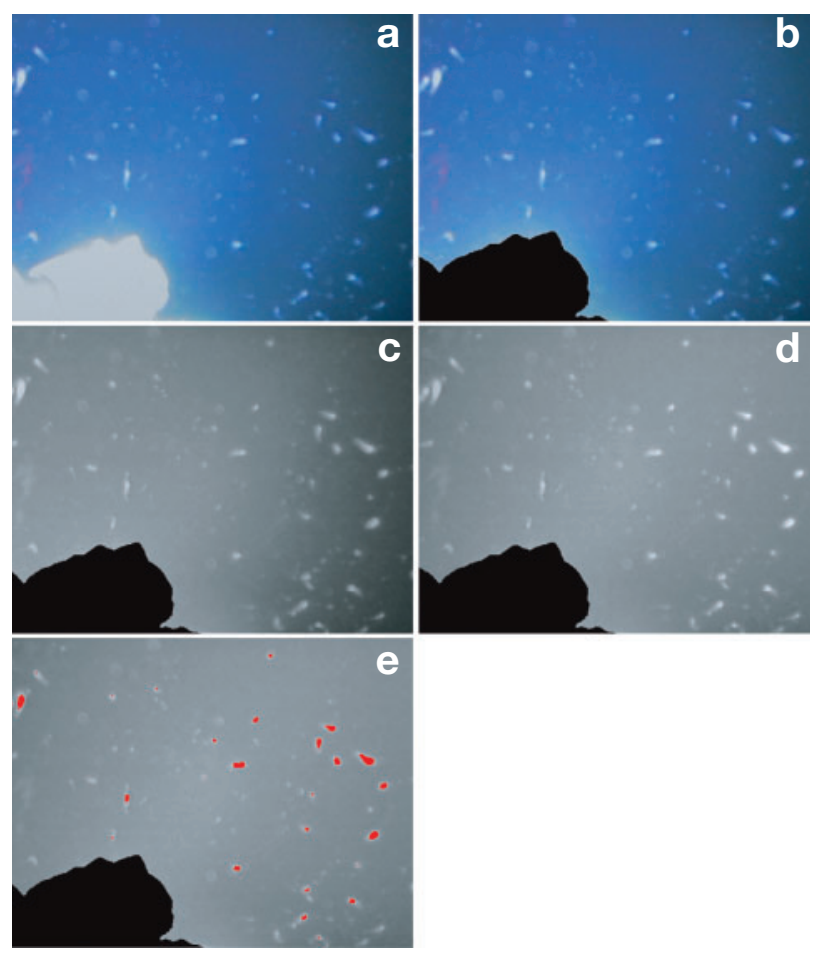

Fig. 3. Example steps involved in processing the image data. (a) An original image; (b) a black mask is used to exclude the area of the image occupied by the other data logger; (c) converting the image to 256 gray-scale image; (d) making the background brightness uniform across all images; (e) identifying prey-like objects according to their brightness ratio

back Island and between 250 and $350 \mathrm{~m}$ for seals at Turks Head. There was no apparent diurnal variability in the dive depths of the 8 seals. A 1-way ANOVA showed that the mean dive depths in each $2 \mathrm{~h}$ bin did not vary significantly with time of day $(p=0.28)$.

For dives with a maximum depth deeper than $50 \mathrm{~m}$, the DSLs provided a total of 1352 images (ranging from 128 to 461 images for each seal) for the 4 Big Razorback Island seals, and 1940 images (ranging from 434 to 519 images for each seal) for the 4 Turks Head seals (Table 1). The sea bottom could be seen on 45 of these
3292 images (1\%) and these images were removed from the analysis. Likewise, there were 8 images $(0.2 \%)$ showing the sea ice. All of them were taken at depths shallower than $18 \mathrm{~m}$, either at the beginning or the end of dives, and therefore were also not included in the analysis. Fig. 4c,d presents the vertical prey distribution as estimated from the images. At Big Razorback Island, the prey index at 250 to $300 \mathrm{~m}$ was significantly higher than at 200 to $250 \mathrm{~m}$ (Scheffé's test, $\mathrm{p}<0.05$ ) (Fig. 4c), yet there was no other significant difference in prey index between other neighboring depths. At Turks Head there were no neighboring depths where prey indices were significantly different (Fig. 4d). As the minimum prey index at each depth was zero for both sites, the maximum value represented the range of the index. The maximum values at 250 to 300 m for Big Razorback Island (32.6) and Turks Head (49.3) were larger than any other depth, which ranged from 0.2 to 18.1 and 0.7 to 11.3 at the 2 sites respectively. Overall, Big Razorback Island had a significantly higher prey index than Turks Head (MannWhitney $U$-test, $\mathrm{p}<0.0001$ ).

Fig. 5 illustrates the typical relationship between prey index and dive profile (depth/time). During the bottom phase, the seal 'Elizabeth' exhibited some movement in the vertical axis, and the prey index at the bottom phase for all 8 seals was significantly higher than either during the descent or ascent phases (Scheffé's test, $\mathrm{p}<0.05$ and $\mathrm{p}<0.005$, respectively) (Fig. 6). Additionally, there was no significant difference in prey index between the descent and ascent phases.

\section{DISCUSSION}

The most frequent dive depth at Big Razorback Island ( 250 to $300 \mathrm{~m}$ ) corresponded with the depth at which the prey index was significantly higher than at shallower depths (Fig. 4a,c). Similarly, the frequencies of dive depths at Turks Head (250 to $350 \mathrm{~m}$ ) also corresponded with higher prey-index values (Fig. 4b,d). This suggests

Table 1. Leptonychotes weddellii. Data length and descriptions for each seal. DSL: Digital Still picture Logger

\begin{tabular}{|c|c|c|c|c|c|}
\hline Site & $\begin{array}{l}\text { Name of } \\
\text { seal }\end{array}$ & Data length & $\begin{array}{l}\text { No. of deep } \\
\text { dives }(>50 \mathrm{~m})\end{array}$ & $\begin{array}{c}\text { Dive depth } \\
\left(\mathrm{m}_{;} \text {mean } \pm \mathrm{SD}\right)\end{array}$ & $\begin{array}{l}\text { No. of DSL } \\
\text { images }\end{array}$ \\
\hline \multirow{5}{*}{$\begin{array}{l}\text { Big Razorback } \\
\text { Island }\end{array}$} & Elizabeth & $28 \mathrm{~h} 43 \mathrm{~min}$ & 10 & $278.6 \pm 18.0$ & 354 \\
\hline & Flaca & $51 \mathrm{~h} 20 \mathrm{~min}$ & 5 & $203.4 \pm 69.9$ & 128 \\
\hline & Marilyn & $11 \mathrm{~h} 51 \mathrm{~min}$ & 12 & $232.3 \pm 102.6$ & 409 \\
\hline & Sophie & $27 \mathrm{~h} 14 \mathrm{~min}$ & 15 & $210.0 \pm 111.8$ & 461 \\
\hline & Total & 119 h 08 min & 42 & $231.9 \pm 94.4$ & 1352 \\
\hline \multirow[t]{5}{*}{ Turks Head } & Crystle & 20 h $04 \mathrm{~min}$ & 14 & $289.8 \pm 90.3$ & 499 \\
\hline & Madonna & $21 \mathrm{~h} 07 \mathrm{~min}$ & 14 & $314.2 \pm 27.3$ & 519 \\
\hline & Martha & 17 h 29 min & 11 & $263.9 \pm 65.9$ & 434 \\
\hline & Wendy & 7 h 36 min & 16 & $304.8 \pm 90.0$ & 488 \\
\hline & Total & $87 \mathrm{~h} 16 \mathrm{~min}$ & 55 & $295.2 \pm 76.3$ & 1940 \\
\hline
\end{tabular}



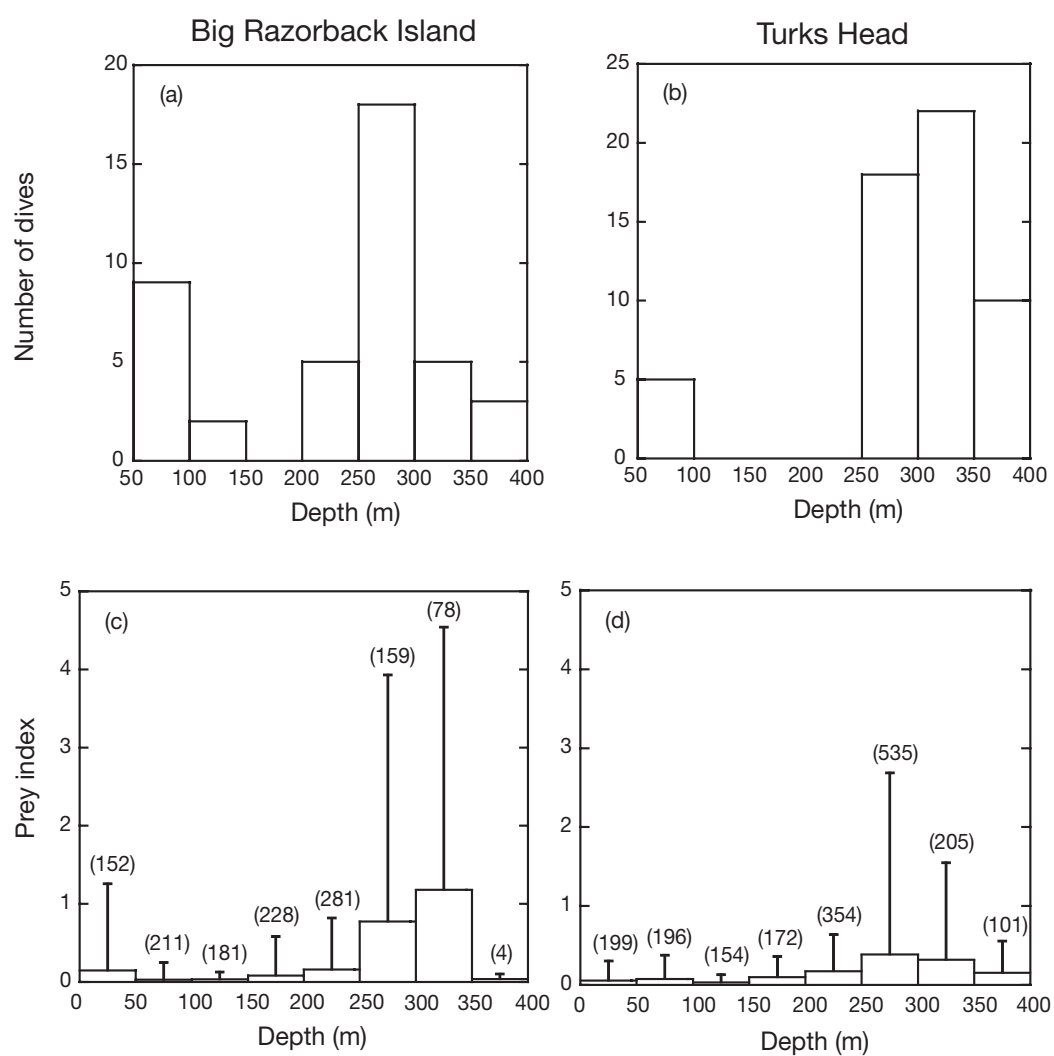

Fig. 4. Leptonychotes weddellii. Histogram of maximum dive depths of (a) 4 seals at Big Razorback Island and (b) 4 seals at Turks Head. Prey index at each depth (mean + SD) at (c) Big Razorback Island and (d) Turks Head with sample size in parentheses

that the seals' dive depths might be affected by the vertical distribution of prey. At both sites the most frequent dive depths were also those with the widest range in abundance (i.e. from zero to the maximum prey index), indicating that seals diving to these depths would not always encounter prey because it might have a patchy distribution in the horizontal axis. This is consistent with the Eastman (1985) and Fuiman et al. (2002) suggestions that Pleuragramma antarcticum may live in shoals.

Previous studies utilizing data from TDRs have primarily described diving behavior subjectively according to perceived similarities in the maximum depth, duration, and general appearance of the dive profile (Kooyman 1968, Le Boeuf et al. 1992, Schreer \& Testa 1995, 1996, Burns et al. 1997). Those portions of dives possessing certain characteristics were assumed to represent specific behaviors such as foraging. In the present study, we have presented direct evidence that the bottom phase of a dive was associated with a significantly higher prey index than the descent and ascent phases, indicating that seals primarily encountered prey near the maximum depth of their dive.

At Big Razorback Island, the prey index between 250 and $350 \mathrm{~m}$ was significantly higher than at shallower depths, and the seals' maximum dive depth was concentrated at the shallower end of the range (250 to $300 \mathrm{~m}$ ) (Fig. 4a,c). Mori (1998) presented a theoretical model which predicted that the optimal foraging depth for a diver would always be shallower than the depth at which prey density was the highest, even if the highest prey density was within easy reach of a diver. Diving cost should increasingly accelerate with dive depth while the same is not necessarily true for prey density (Y. Mori pers. comm.). At the time there were no data available to test the prediction; however, our research lends support to the validity of the theoretical model.

Although the prey index from 250 to $350 \mathrm{~m}$ was relatively high at both sites (Fig. 4c,d), the seals at Big Razorback Island dived significantly shallower than the seal at Turks Head (Fig. 4a,b). One hypothesis for this apparent discrepancy is that extra effort and time would be necessary for a seal to reach deeper depths at Big Razorback Island because of the shallow body angles required by local bathymetry and the orientation of cracks (Fig. 1b,c) (Sato et al. 2003). Additionally, more dives to $50-100 \mathrm{~m}$ were observed at Big Razorback Island than at Turks Head (Fig. 4a,b). A seal we referred to as 'Sophie' performed 6 of the total 9 dives to $50-100 \mathrm{~m}$ at Big Razorback Island and $50 \%$ of the images from these dives showed the seafloor. These dives had minimal vertical movement during the bottom phases, suggesting that Sophie might have remained on or at the bottom. Burns et al. (1998) stated that Weddell seals in the pelagic zone foraged pri-

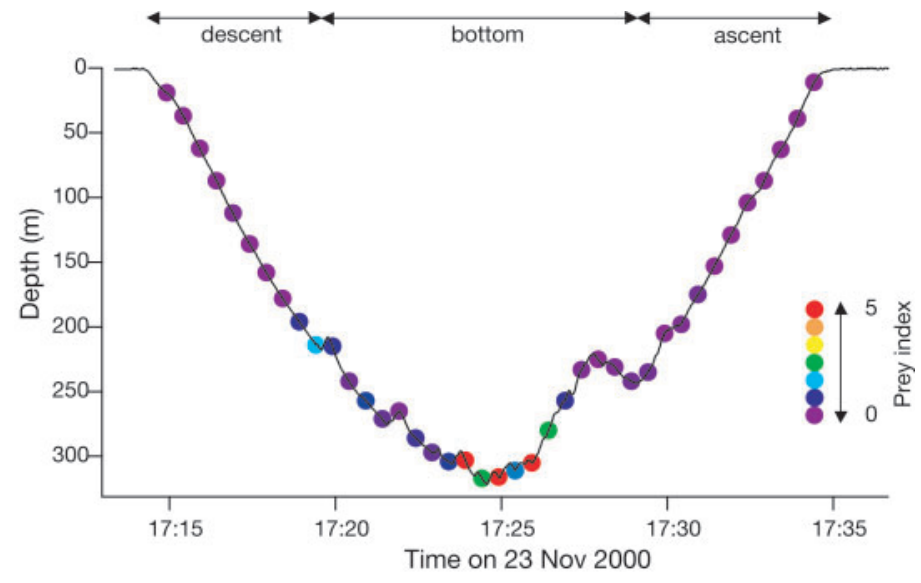

Fig. 5. Example relationship between prey index and a dive profile. This dive was performed by the seal referred to as 'Elizabeth' at Big Razorback Island. Circles on the dive profile represent the moment when an image was taken. The color of the circle represents the prey index (red for high values and purple for low values) 


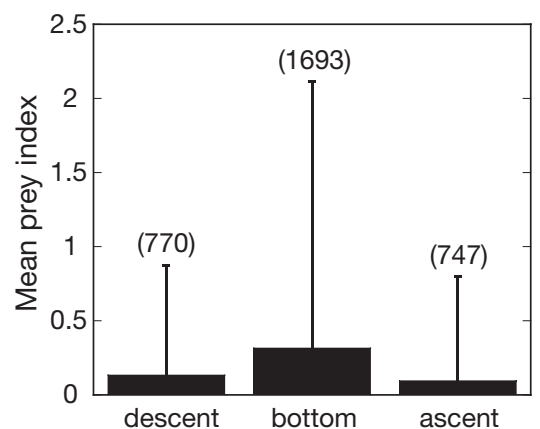

Fig. 6. Leptonychotes weddellii. Prey index of each phase of a dive (mean + SD). Data for all 8 seals (Big Razorback Island; $\mathrm{n}=4$ and Turks Head; $\mathrm{n}=4$ ) were used. The prey index at the bottom phase was significantly higher than the descent or ascent phase (Scheffé's test, $\mathrm{p}<0.05$ and $\mathrm{p}<0.005$, respectively). Number of samples is in parentheses

marily on Pleuragramma antarcticum while shallow-diving seals foraged mainly on benthic fish like Trematomus spp. Green \& Burton (1987) also reported that Weddell seals tended to take prawns like Chorismus spp. in shallower water, but in deeper waters they took fish more readily. Therefore dives to $50-100 \mathrm{~m}$ observed in this study might correspond to foraging dives focused on benthos. This is consistent with the suggestion of Plötz et al. (2001) that Weddell seals might primarily forage within 2 depth layers.

Plötz et al. (2001) suggested that Weddell seals might prefer to forage deeper during daylight and shallower during darkness, and that the diurnal pattern in dive depth might be finely tuned to vertically migrating prey (e.g. Pleuragramma antarcticum). Fuiman et al. (2002) also demonstrated a diel migration by $P$. antarcticum that might be directly related to ambient light intensity. If true, our lack of evidence for diurnal pattern in foraging depths may be related to the lower variability in light intensity during the middle of the austral summer. Experiments by Plötz et al. (2001) and Fuiman et al. (2002) were conducted during the lateand early-austral summer, respectively.

Acknowledgements. We thank C. Counard, S. Dahle, D. MacNulty, K. Krysl, H. Reider, E. Morton, and G. Wong for their assistance with the fieldwork. Special thanks are due to N. Miyazaki and I. Aoki for their helpful comments. The experimental protocol was previously approved by the National Marine Fisheries Service. This work was conducted under grants from the National Science Foundation (OPP-9420818) and a Grant-in-Aid from the Japan Society for the Promotion of Science (11691197, 14405027, 13460082 and 12NP0201).

\section{LITERATURE CITED}

Burns JM, Schreer JF, Castellini MA (1997) Physiological effects on diving patterns and foraging strategies in yearling Weddell seals (Leptonychotes weddellii). Can J Zool 75:1796-1810
Burns JM, Trumble SJ, Castellini MA, Testa JW (1998) The diet of Weddell seals in McMurdo Sound, Antarctica as determined from scat collections and stable isotope analysis. Polar Biol 19: $272-282$

Castellini M, Davis R, Davis M, Horning M (1984) Antarctic marine life under the McMurdo ice shelf at White Island: a link between nutrient influx and seal population. Polar Biol 2:229-231

Davis RW, Wartzok D, Elsner R, Stone H (1992) A small video attached to a Weddell seal: a new way to observe diving behavior. In: Thomas JA, Kastelein RA, Supin AY (eds) Marine mammal sensory systems. Plenum Press, New York, p 631-642

Davis RW, Fuiman LA, Williams TM, Collier SO, Hagey WP, Kanatous SB, Kohhin S, Horning M (1999) Hunting behavior of a marine mammal beneath the Antarctic fast ice. Science 283: 993-995

DeWitt HH (1970) The character of the midwater fish fauna of Ross Sea, Antarctica. In: Holdgate MW (ed) Antarctic ecology, Vol I. Academic Press, London, p 305-314

Eastman JT (1985) Pleuragramma antarcticum (Pisces, Nototheniidae) as food for other fishes in McMurdo Sound, Antarctica. Polar Biol 4:155-160

Everson I (1984) Fish biology. In: Laws RM (ed) Antarctic ecology, Vol II. Academic Press, London, p 491-532

Fuiman LA, Davis RW, Williams TM (2002) Behavior of midwater fishes under the Antarctic ice: observation by a predator. Mar Biol 140:815-822

Green K, Burton HR (1987) Seasonal and geographical variation in the food of Weddell seals, Leptonychotes weddellii, in Antarctica. Aust Wildl Res 14:475-489

Hooker SK, Boyd IL, Jessopp M (2002) Monitoring the prey-field of marine predators: combining digital imaging with datalogging tags. Mar Mamm Sci 18:680-697

Kooyman GL (1968) An analysis of some behavioral and physiological characteristics related to diving in the Weddell seals. Antarct Res 11:227-261

Kusagaya H, Sato K (2001) A safe and practical inhalation anaesthesia for Weddell seals. Polar Biol 24:549-552

Le Boeuf BJ, Naito Y, Asaga T, Crocker D, Costa DP (1992) Swim speed in a female northern elephant seal: metabolic and foraging implications. Can J Zool 70:786-795

Macdonald JA, Montgomery JC, Wells RMG (1987) Comparative physiology of Antarctic fishes. Adv Mar Biol 24:321-360

Mori Y (1998) Optimal choice of foraging depth in divers. J Zool Lond 245:279-283

Naito Y, Le Boeuf BJ, Asaga T, Huntley AC (1989) Long-term records of an adult female northern elephant seal. Antarct Rec 33:1-9

Plötz J, Bornemann H, Knust R, Schröder A, Bester M (2001) Foraging behaviour of Weddell seals, and its ecological implications. Polar Biol 24:901-909

Ponganis PJ, Vandam RP, Marshall G, Knower T, Levenson DH (2000) Sub-ice foraging behavior of emperor penguins. J Exp Biol 203:3275-3278

Sato K, Mitani Y, Cameron MF, Siniff DB, Watanabe Y, Naito Y (2002) Deep foraging dives in relation to the energy depletion of Weddell seal (Leptonychotes weddellii) mothers during lactation. Polar Biol 25:696-702

Sato K, Mitani Y, Cameron MF, Siniff DB, Naito Y (2003) Factors affecting stroking patterns and body angle in diving Weddell seals under natural conditions. J Exp Biol 206:1461-1470

Schreer JF, Testa JW (1995) Statistical classification of diving behavior. Mar Mamm Sci 11:85-93

Schreer JF, Testa JW (1996) Classification of Weddell seal diving behavior. Mar Mamm Sci 12:227-250

Stirling I (1966) A technique for handling live seals. J Mamm $47: 543-544$

Submitted: October 21, 2002; Accepted: January 28, 2003

Proofs received from author(s): April 8, 2003 